\title{
Application of ergonomic guidelines during minimally invasive surgery: a questionnaire survey of 284 surgeons
}

\author{
L. S. G. L. Wauben ${ }^{1}$, M. A. van Veelen ${ }^{1}$, D. Gossot ${ }^{2}$, R. H. M. Goossens ${ }^{1}$ \\ ${ }^{1}$ Delft University of Technology, Faculty of Industrial Design Engineering, Landbergstraat 15, 2628 CE, Delft, The Netherlands \\ ${ }^{2}$ Thoracic Department, Institut Mutualiste Montsouris F-75014, Paris, France
}

\begin{abstract}
Background: This study aimed to obtain an answer for the question: Are ergonomic guidelines applied in the operating room and what are the consequences?

Methods: A total of 1,292 questionnaires were sent by email or handed out to surgeons and residents. The subjects worked mainly in Europe, performing laparoscopic and/or thoracoscopic procedures within the digestive, thoracic, urologic, gynecologic, and pediatric disciplines.

Results: In response, $22 \%$ of the questionnaires were returned. Overall, the respondents reported discomfort in the neck, shoulders, and back (almost $80 \%$ ). There was not one specific cause for the physical discomfort. In addition, $89 \%$ of the 284 respondents were unaware of ergonomic guidelines, although $100 \%$ stated that they find ergonomics important.

Conclusion: The lack of ergonomic guidelines awareness is a major problem that poses a tough position for ergonomics in the operating room.
\end{abstract}

Key words: Endoscopy — Human factors - MIS — Operating room — Physical complaints

\section{Introduction}

The advantages of minimally invasive surgery (MIS) for the patient are already well known. On the other hand, the disadvantages for the surgeon and the operating team also are becoming increasingly known [15]. Ergonomic research strives to improve the working conditions in the operating room. The word ergonomics originates from the Greek words "ergon" (labor) and "nomos" (law), which indicate knowledge concerning the law of human labor. Combined with product development and product evaluation, this leads to the working principle that the operating room designers should "adapt the environment to the workers instead of adapting the workers to their environment" [6].

Ergonomic research has led to the ergonomic guidelines presented in the literature, which deal with the placing of equipment in an ergonomic position and with ergonomic postures of the operating team to prevent discomfort $[4,7-11,16]$. Also during congresses, ergonomic items are introduced.

More detailed guidelines for different variables in the operating room are stated concerning the table height $[4,9,11,16]$, the monitor placement $[8,9,13,15-17]$, the instrument's handle design $[1,3,5$, $10,16]$, the foot pedals [20], and the physical discomfort of the operating team $[2,10,12,18,19]$. Still, the question is whether these guidelines are known and used.

This study aimed to obtain an answer to the question: Are ergonomic guidelines applied in the operating room and what are the consequences? This question was divided into three subquestions:

1. To what extent are surgeons aware of ergonomic guidelines?

2. Are these guidelines being applied during MIS?

3. Do surgeons expect a relation between physical complaints and the apparatus and equipment used?

\section{Material and methods}

Inclusive criteria

The research was conducted in cooperation with the Delft University of Technology and the European Association for Endoscopic Surgery (EAES). The target group for this study included surgeons and residents who perform laparoscopic or thoracoscopic procedures within the digestive, thoracic, urologic, gynecologic, and pediatric disciplines. In addition, the subjects from the target group had to be capable of reading the English language to understand and complete the questionnaire correctly. 
The survey was conducted by means of a questionnaire. Both the member database of the EAES and the database used in the research of Schoofs and Gossot [14] were used for sending the questionnaires by email. A total of 1,142 emails were sent to European surgeons and residents, 990 of whom were members of the EAES at the time. The subjects received an email with an explanation of the study aim and were asked to fill out the questionnaire on the Internet. Also, 150 hard copies of the questionnaire were handed out at national and international congresses including the OR of the Future and Robotics in Leeuwarden from 31 October to 2 November 2004, the Endo Club Nord in Hamburg from 4 to 6 November 2004, and the SMIT (The Society for Medical Innovation and Technology) in Rome from 16 to 18 December 2004.

\section{Questionnaire}

The questionnaire included questions concerning table height, monitor position and height, use of foot pedals, physical complaints caused by the apparatus and equipment, and awareness of ergonomic guidelines. The 40 questions were arranged in separate chapters. A total of 22 questions could be answered by marking given answers.

The Internet version of the questionnaire called for the use of option buttons when only one answer could be given, and checkboxes when several answers could be given. For three questions, a category termed "other" was used in addition to the given answers. For example, the question "What kind of monitors are used?" was accompanied with the answers "flat screen(s)," "regular (CRT (Cathode Ray Tube)) monitor(s)," "projection screen(s)," and "other (please describe below)." Of the 18 open questions, 10 were preceded by the given answers "yes" or "no." The hard copy of the questionnaire was similar to the Internet version, except that the hard copy was in black and white and all the multiple answer possibilities were preceded with bullets. Table 1 presents a summarized version of the questionnaire.

Table 1. Summarized version of the questionnaire

\section{General}

- What kind of endoscopic procedures do you perform?

- How many hours a day (mean time) do you perform endoscopic procedures?

Table height (distance from the top of the table to the floor)

-What is normally the table height during the incision and placement of the trocars?

- What is the table height during the actual operation?

- How would you rate the table height?

- Do you think the height range of the operating table is appropriate for endoscopic surgery? If your answer is no, should it be possible to lower or raise it more, or both? Indicate your extent of agreement, from 0 (I do not agree) to 5 (I fully agree), with the next propositions.

- I experience discomfort in my neck due to a bad table height.

- I experience discomfort in my shoulders due to a bad table height.

Monitor

- How many monitors are used?

- What kind of monitors are used?

- Where are the monitors placed?

- Are you hindered by the position of the monitors? If yes, how are you hindered?

Indicate your extent of agreement, from 0 to 5 with the next propositions.

- I experience discomfort in my neck due to a bad monitor height.

- I experience discomfort in my neck due to a bad monitor position.

Foot pedal

-What do you use to activate the diathermic or the ultrasonic equipment?

- Do you find the use of the commonly used foot pedals comfortable?

- How would you prefer to control the diathermic or the ultrasonic equipment?

Indicate your extent of agreement, from 0 to 5, with the next propositions?

- I experience discomfort in my legs and foot due to use of the foot pedals.

Physical complaints

- Rate your physical discomfort, from 0 (no pain) to 5 (severe pain), in the different

body areas.

Guidelines

- Are you aware of any guidelines for endoscopic surgery in the literature concerning

the table height and placement of the monitor and instruments?

- Do you think that the ergonomic conditions in the operating room are important?

\section{Results}

From the 1,292 contacted subjects, 252 responded via the Internet and 32 filled out the hard copy of the questionnaire, for a total of 284 respondents and a response rate of $22 \%$. A total of 254 surgeons and 30 residents responded. The characteristics of the respondents are presented in Table 2. 
Table 2. Characteristics of the 284 respondents

\begin{tabular}{l|ll}
\hline Gender: 254M/30F & \multicolumn{2}{|l}{ Respondents (\%) } \\
\hline & $<500$ & 29 \\
Experience (no. of procedures): & $500-1000$ & 23 \\
& $1000-2000$ & 22 \\
& $>2000$ & 26 \\
\hline \multirow{2}{*}{ Mean operating time (h/day): } & $<1$ & 19 \\
& $1-2$ & 41 \\
& $2-5$ & 33 \\
\hline Mean height (cm): & $>5$ & 7 \\
\hline Mean age (years): & $178 \pm 7.5$ \\
\hline
\end{tabular}

Most of the respondents (55\%) performed MIS within the discipline of digestion, followed by $22 \%$ within the thoracic discipline, 10\% within the discipline of gynecology, $6 \%$ within the discipline of urology, and $7 \%$ within the discipline of pediatrics. The respondents worked mainly in Europe $(\mathrm{n}=$ 260). Figure 1 shows the countries in which the largest number respondents worked. Other European countries were represented with fewer than eight respondents per country. From Fig. 1, it can be seen that most of the respondents $(n=74,27 \%)$ worked in the Netherlands.

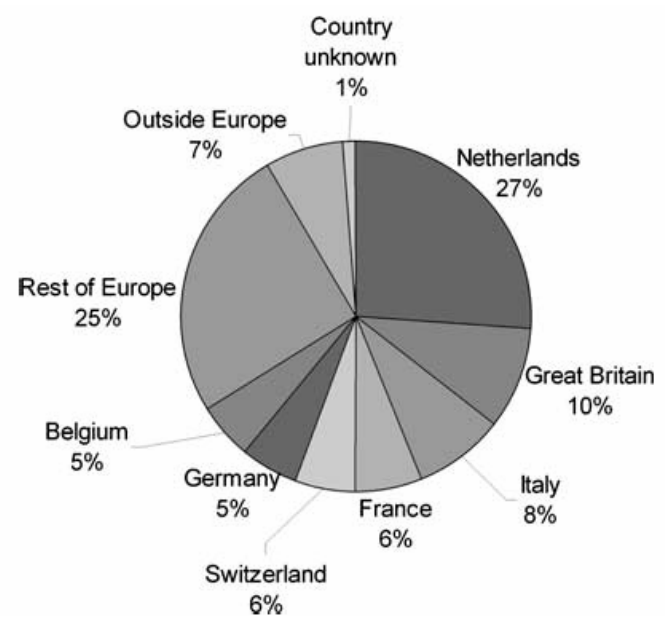

Fig. 1. Respondents' place of work.

Table height

During the current study, the table height was defined as the distance from the table top to the floor. This means that when the table was tilted, the table top height was measured in terms of the pubic and navel height at the standing position of the surgeon.

It can be seen from Fig. 2a that during the incision and placement of the trocars, the height of the operating table was placed mainly at navel height (55\%). During the actual operation, the table was placed mainly at pubic height (60\%), as can be seen in Fig. $2 \mathrm{~b}$.
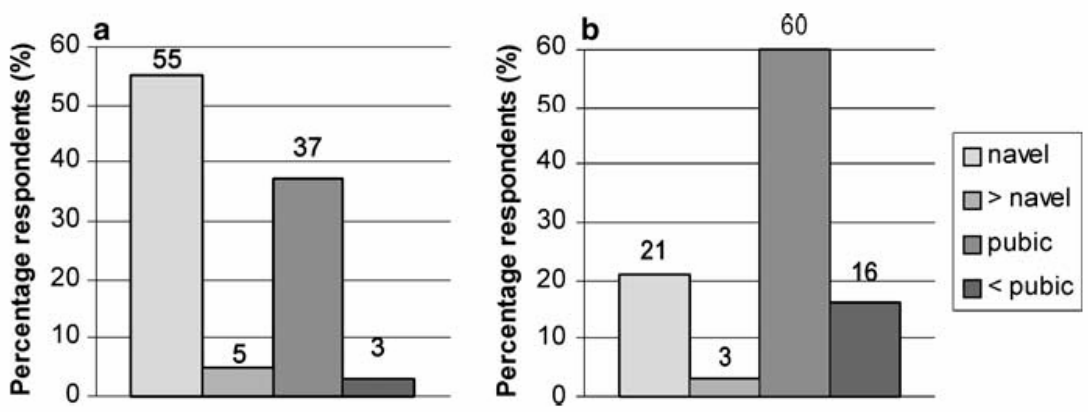

Fig. 2. Table height during incision and placement of the trocars (a) and during the actual operation (b). 
Figure 3 shows that $45 \%$ of the respondents found the height range of the operating table inadequate for endoscopic surgery and preferred a different height range. Most of the respondents (70\%) wanted the table equipped to be lowered more; $4 \%$ wanted the table equipped to be raised more; and $26 \%$ wanted both.

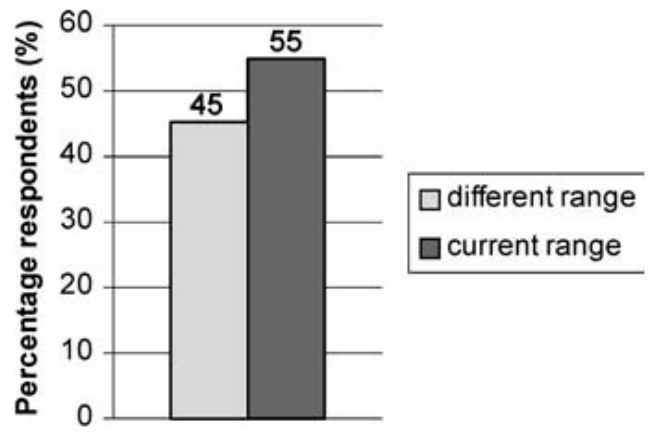

Fig. 3. Table height preference.

The respondents also were asked to indicate the extent of their agreement with the propositions concerning the table height, such as those describing discomfort in the neck and shoulders. Figure $4 \mathrm{a}$ shows that $64 \%$ of the respondents agreed, from somewhat to fully, with the proposition that a bad table height causes physical discomfort in the neck. It can be seen that $14 \%$ of the respondents even fully agreed, showing that a nonergonomic table height indeed causes neck complaints. It can be seen from Fig. $4 \mathrm{~b}$ that $77 \%$ agreed, from somewhat to fully, with the proposition that a bad height of the operating table causes discomfort in the shoulders. In this case, $18 \%$ of the respondents fully agreed, indicating that a nonergonomic table height causes shoulder complaints. In addition, Fig. 4c shows a surgeon who has to raise her shoulders and arms to operate the instruments because the table is placed too high.
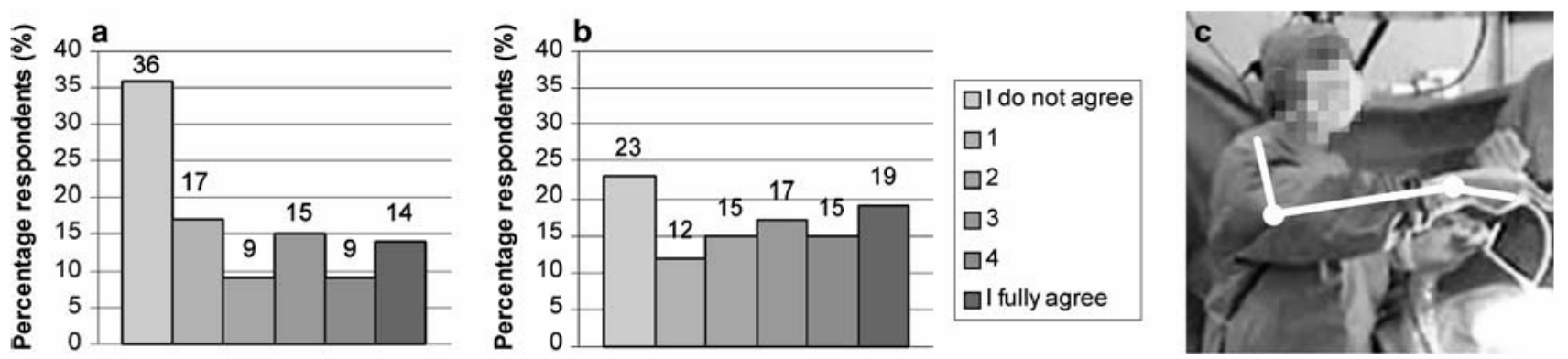

Fig. 4. a "I experience discomfort in my neck due to a bad table height." b "I experience discomfort in my shoulders due to a bad table height." c Raising of the shoulders to control the instrument.

\section{Monitor}

Figure 5 a shows that during most of the endoscopic operations, one or two monitors were used. In most cases, a regular CRT monitor was used (80\%). In the remaining cases, a flat screen (19\%) or a projection screen (1\%) was used. Most monitors $(71 \%)$ were placed on an instrument tower without height adjustment. In all other cases, the monitor was placed on a movable arm with (19\%) or without $(10 \%)$ height adjustment. Figure $5 \mathrm{~b}$ shows that most of the respondents $(77 \%)$ were not being hindered by the position of the monitor, and Fig. 6 shows that most of the respondents (64\%) were satisfied with the current position of the monitor. 

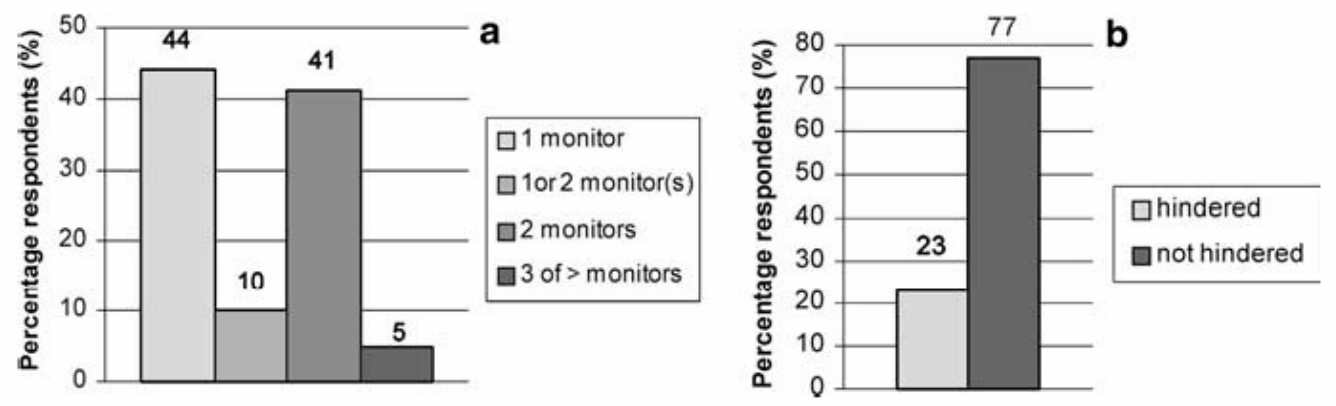

Fig. 5. a Number of monitors. b Hindering of the monitor position.

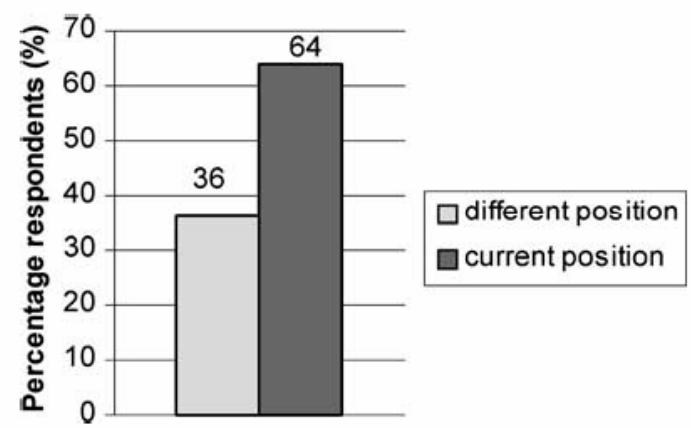

Fig. 6. Monitor position preference.

Again, the respondents were asked to indicate the extent of their agreement with propositions concerning discomfort in the neck because of bad monitor height and position. Figure 7a shows that $70 \%$ of the respondents agreed, from somewhat to fully, with the proposition that a bad monitor height causes discomfort in the neck, and that $16 \%$ even fully agreed, indicating that neck complaints are caused by a nonergonomic monitor height. In addition, Fig. $7 \mathrm{~b}$ shows that the surgeon must flex her neck to look at the monitor, which is placed too high.
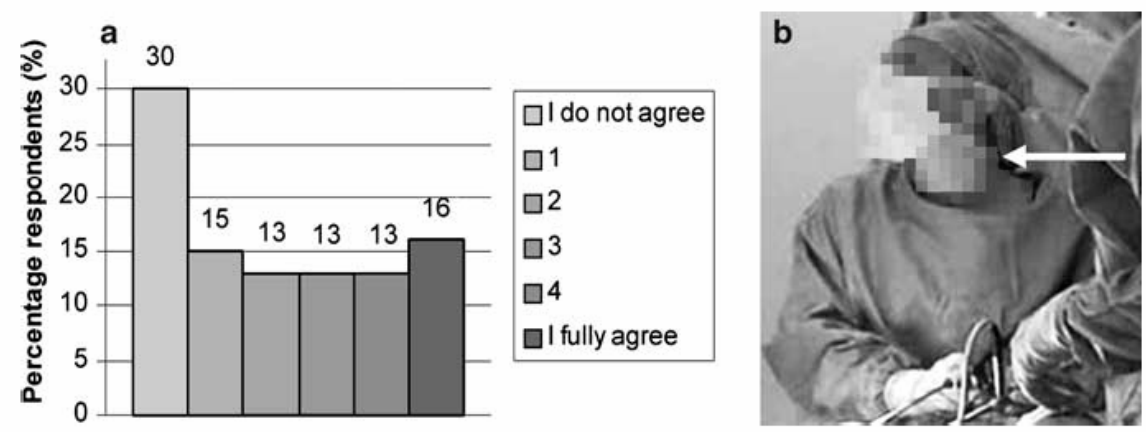

Fig. 7. a "I experience discomfort in my neck due to a bad monitor height." b Flexion of the neck.

Figure 8 a shows that $74 \%$ of the respondents agreed, from somewhat to fully, with the proposition that a bad monitor position causes discomfort in the neck, and that $23 \%$ even fully agreed with the statement, implying that a nonergonomic monitor position causes discomfort in the neck. Also, Fig. 8b shows an example of a bad monitor position causing neck complaints. The assisting surgeon must rotate his neck during the entire operation to look at the monitor placed next to him. 
a

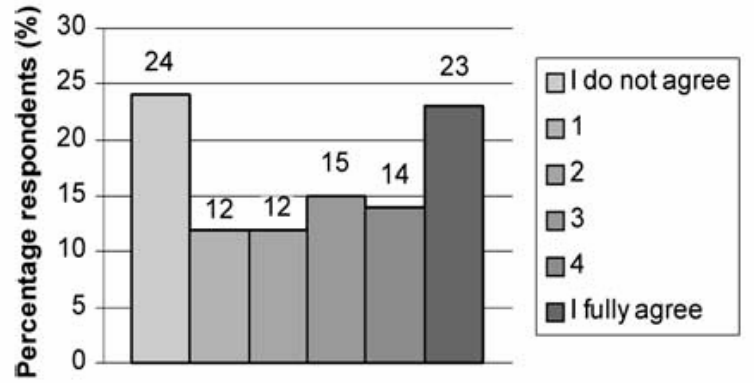

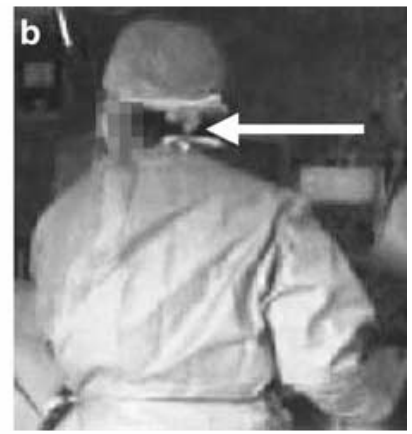

Fig. 8. a "I experience discomfort in my neck due to a bad monitor position." b Rotation of the neck to view the monitor.

\section{Foot pedal}

Most respondents (87\%) used a foot pedal to control the diathermic or ultrasonic equipment (Fig. 9). Sometimes a hand control was used (13\%). The use of the foot pedals was found to be uncomfortable by a little more than half of the respondents (53\%). The following were mentioned:

- There is no visual control over the pedal; the pedal gets lost and is hard to find beneath the table $(n=64)$.

- The operator has to stand on one foot, which can disturb the balance $(n=30)$.

- Too many pedals are used during surgery $(n=13)$.

- It is difficult to switch the surgeon's side of the patient during surgery $(n=10)$.

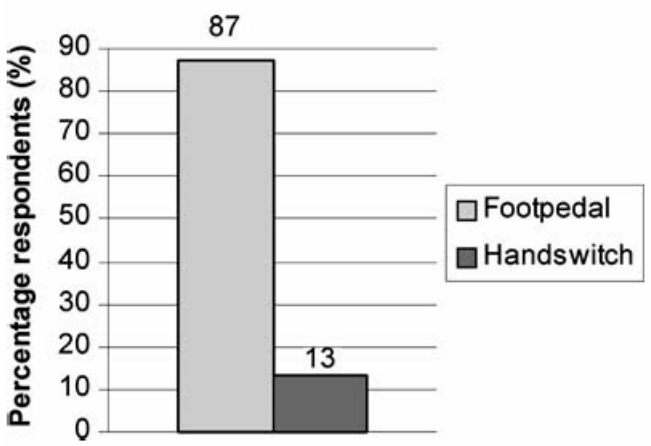

Fig. 9. Controlling the diathermic or ultrasonic equipment.

By means of an open question, the respondents were asked how they would rather prefer controlling the diathermic or ultrasonic equipment. It can be seen from Fig. 10 that the majority (53\%) wanted to control the diathermic or the ultrasonic equipment in a different way. Of these, $72 \%$ wanted to control it by means of a hand control, $8 \%$ by voice, and $20 \%$ in an alternative way (e.g., infrared navigation, device in the shoe, more ergonomic pedals, and device attached to the foot).

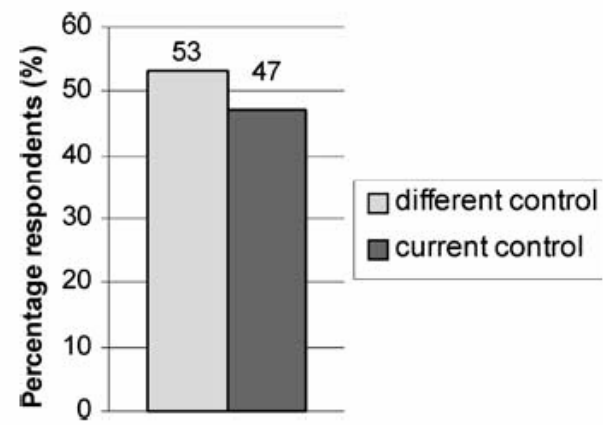

Fig. 10. Preference for controlling the diathermic or ultrasonic equipment.

Figure $11 \mathrm{a}$ shows that $44 \%$ of the respondents did not agree with the proposition that foot pedals cause discomfort in the legs. Figure $11 \mathrm{~b}$ shows similar results. It can be seen that $43 \%$ did not agree with the statement that foot pedals cause discomfort in the foot. Both figures show that only $5 \%$ fully 
agreed that pedals cause discomfort in the legs and the foot. However, Fig. 11c shows that the surgeon must flex his or her foot to control the foot pedal.
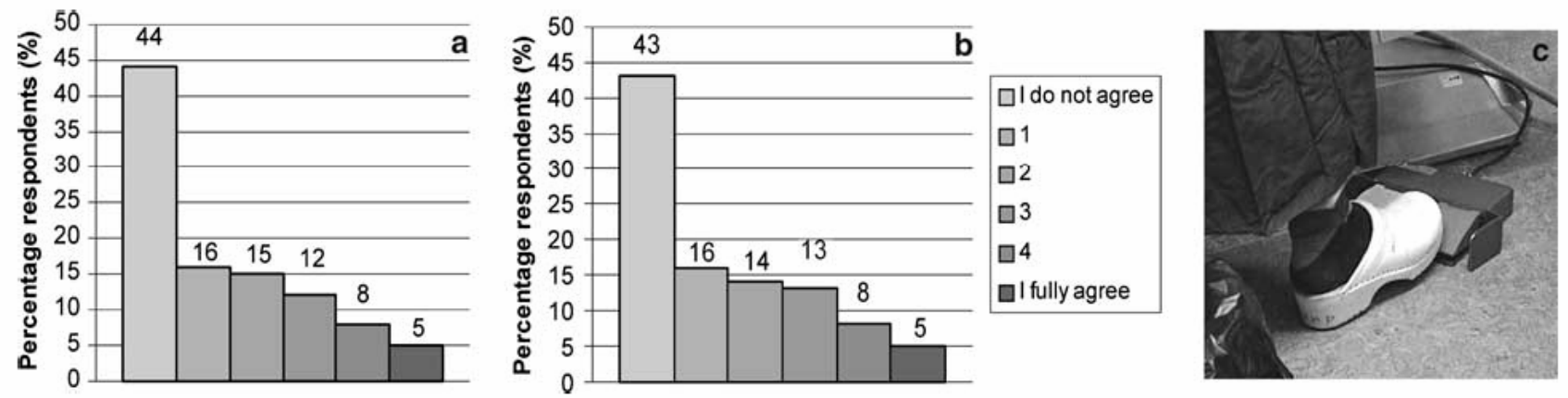

Fig. 11. a "I experience discomfort in my legs due to the use of the foot pedals." $\mathbf{b}$ "I experience discomfort in my foot due to the use of the foot pedals." c Flexion of the foot.

\section{Physical complaints}

The respondents also were asked the extent of their agreement with the following proposition: "I experience muscle fatigue due to the static posture." Figure 12 shows that $88 \%$ agreed, from somewhat to fully, with the statement. This implies that a static posture during MIS causes muscle fatigue.

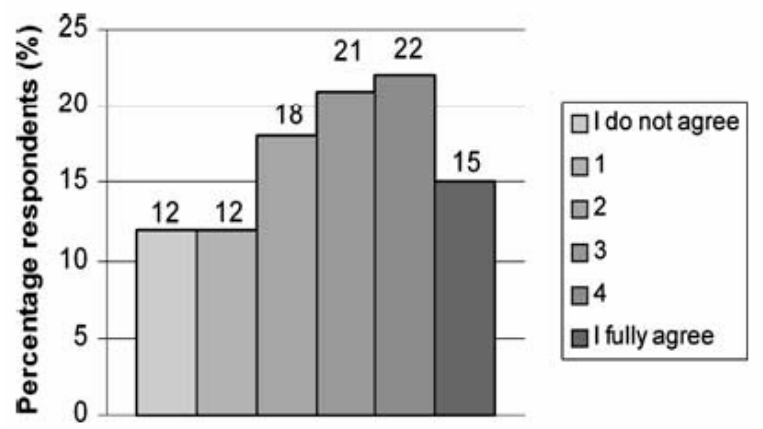

Fig. 12. "I experience muscle fatigue due to the static posture."

The physical discomfort in several parts of the body was rated from 0 (no pain) to 5 (severe pain). The column farthest to the left in Fig. 13 indicates no pain, whereas the remaining columns all indicate discomfort in the particular areas. The most physical complaints concerned the neck, shoulders, and back. Figure 13 shows that almost $80 \%$ of the surgeons and residents experienced discomfort in these areas. 


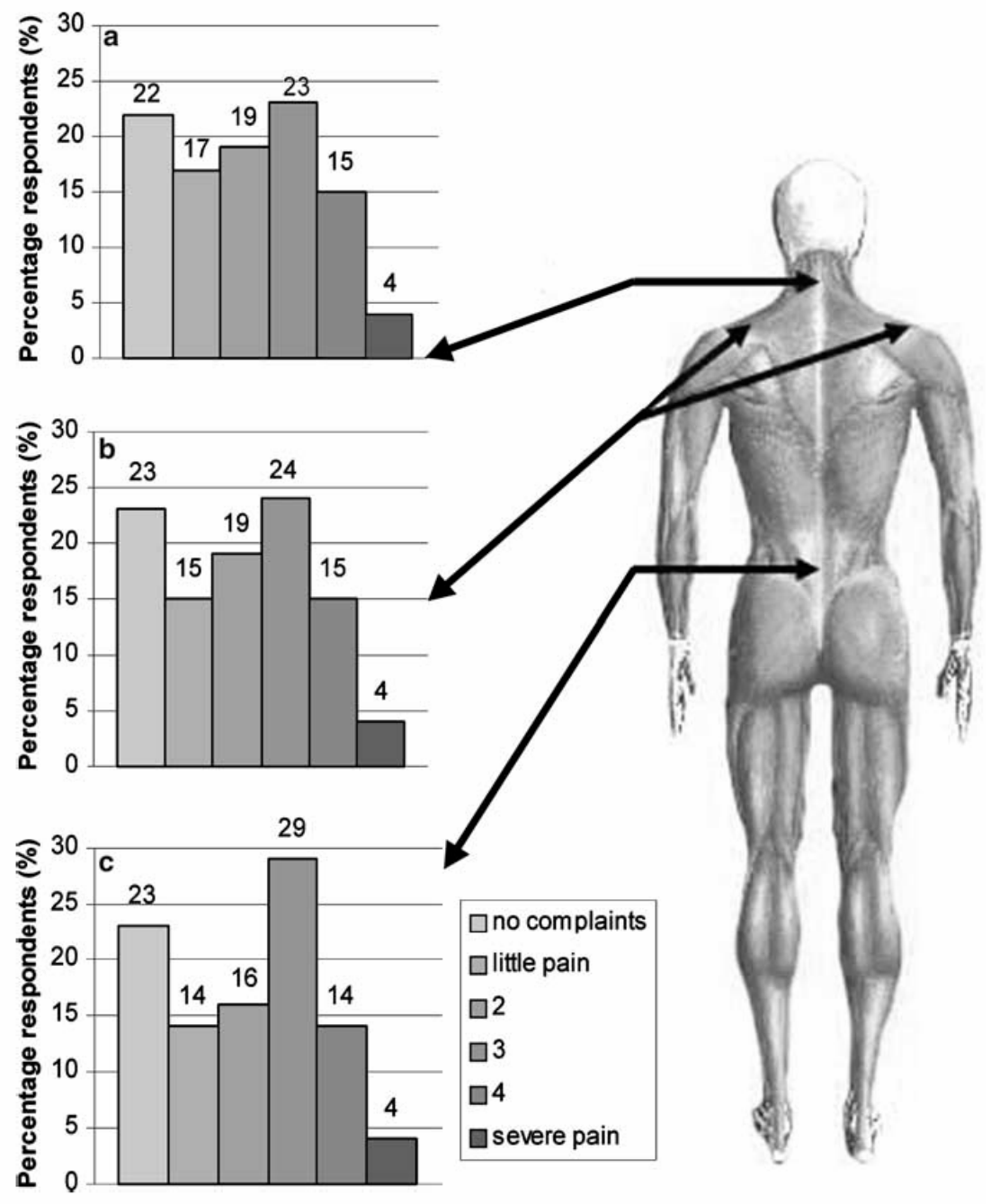

Fig. 13. Percentage of respondents who experience pain in the neck (a), shoulders (b), and back (c).

Finally, all the respondents stated that ergonomics are important in the operating room. However, only $11 \%$ of the respondents were aware of ergonomic guidelines concerning placement of the equipment and apparatus and an ergonomically correct posture (Fig. 14).

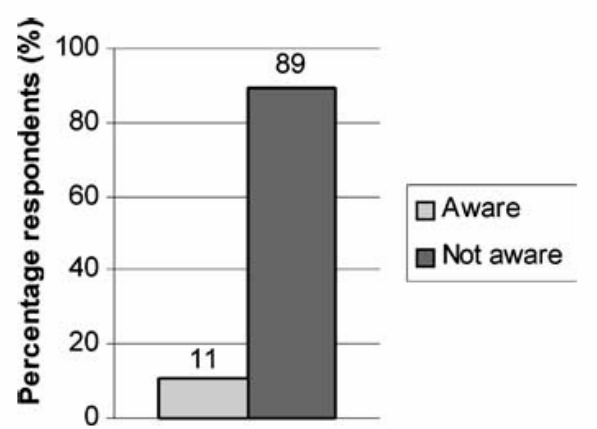

Fig. 14. Awareness of ergonomic guidelines.

\section{Discussion}

At the time of this study, the EAES had approximately 3,895 European members. Of these members, 990 registered an email address, and together with the 152 email addresses of the database of Schoofs and Gossot [14], the questionnaires were sent. Although 284 respondents in comparison with the total of 4,047 is only $7 \%$, the authors assume that the random survey sample still is representative 
for the population of surgeons in Europe. Besides, it is the largest sample survey found in the literature. This large number of respondents gives an adequate image of the problems encountered in the operating room during MIS. In addition, a total of 74 Dutch respondents filled out the questionnaire, which was $25 \%$ of the Dutch EAES members at the time.

Consequently, this gives a representative image of the surgeons and their complaints in the Netherlands. It should be noted that the research was conducted mainly in Europe and thus is valid only for Europe. Besides international differences, differences also can be found between the hospitals in each country. Many operating rooms differ in dimensions, layout, type of monitors (e.g., flat screens, CRT monitors, or projection screens), and placement of the monitors (e.g., at the side, feet, or head of the patient). All these factors, including the personal preferences of the surgeons and residents, make it difficult to compare the comfort level of the operating team during MIS.

During this study, the surgeons and residents had to rate their physical discomfort themselves. These subjective ratings (an objective study requires another approach) could have influenced the results because pain generally is seen as "part of the job" by surgeons and residents. Therefore, the respondents would not complain easily, which could have led to the ratings of relatively little discomfort.

Concerning the table height and the accompanying complaints, it was shown that $64 \%$ of the respondents experienced discomfort in the neck and $77 \%$ had discomfort in the shoulders. However, the operating surface height is even higher than the table height because of the patient and the inflation of the abdomen. Therefore, the physical problems are even worse because the arms and shoulders must be raised even more to control the instruments.

In recent years, many studies on the ergonomics in the operating room have been performed, mainly focused on minimally invasive procedures. These studies are of great importance. Although many ergonomic guidelines have been stated over the years $[4,7-11,15,16]$, this study shows that only $11 \%$ of the respondents were aware of these guidelines. Considering the fact that $100 \%$ of the respondents found ergonomics to be important, it could be stated that ergonomics are inappropriately communicated to the operating team. Ergonomics should be presented as an improvement in the patient's safety. In the end, less discomfort causes less tiring, which leads to fewer mistakes, thereby benefiting the patient because less trauma is inflicted.

\section{Conclusion}

The answers to the questions stated in the introduction are as follows:

1. Notably only $11 \%$ of the 284 questioned surgeons and residents were aware of the ergonomic guidelines for placement of the equipment and ergonomic working postures, whereas $100 \%$ of the respondents stated that they find ergonomics important. It could thus be concluded that this unawareness of ergonomic guidelines is a major problem that poses a tough position for the ergonomics in the operating room.

2. Most respondents are unaware of the guidelines and therefore they are often not applied during MIS. Most of the time, the equipment is used in its initial position, and although possible, it is not adjusted according to the ergonomic guidelines for better comfort.

3. Finally, the research shows that the surgeons and residents found a relation between physical complaints and the apparatus and equipment used. The equipment indeed causes physical complaints. On the other hand, the questionnaire answers generally show relatively little discomfort in all of the researched areas, indicating that there is not one specific cause of physical discomfort.

\section{References}

1. Berguer R (1998) Surgical technology and the ergonomics of laparoscopic instruments. Surg Endosc 12: 458462

2. Berguer R, Forkey DL, Smith WD (1999) Ergonomic problems associated with laparoscopic surgery. Surg Endosc 13: 466-468

3. Berguer R, Gerber S, Kilpatrick G, Beckley D (1998) An ergonomic comparison of in-line vs pistol-grip handle configuration in a laparoscopic grasper. Surg Endosc 12: 805-808

4. Berguer R, Smith WD, Davis S (2002) An ergonomic study of the optimum operating table height for laparoscopic surgery. Surg Endosc 16: 416-421

5. Emam TA, Frank TG, Hanna GB, Cuschieri A (2001) Influence of handle design on the surgeon's limb movements, muscle recruitment, and fatigue during endoscopic suturing. Surg Endosc 15: 667-672

6. Goossens RHM, Van Veelen MA (2001) Assessment of ergonomics in laparoscopic surgery. Min Invas Ther Allied Technol 10: 175-179

7. Hanna GB, Shimi SM, Cuschieri A (1998) Task performance in endoscopic surgery is influenced by location of the image display. Ann Surg 227: 481-484 
8. Matern U, Faist M, Giebmeyer C, Buess G (2005) Monitor position in laparoscopic surgery. Surg Endosc 19: 436-440

9. Matern U, Rückauer KD, Farthmann EH (2000) Die Arbeitshaltung des laparoskopisch tätigen Chirurgen: Ideal und Wirklichkeit. Zentralbl Chir 125: 698-701

10. Matern U, Waller $P$ (1999) Instruments for minimally invasive surgery: principles of ergonomic handles. Surg Endosc 13: 174-182

11. Matern U, Waller P, Giebmeyer C, Rückauer KD, Farthmann EH (2001) Ergonomics: requirements for adjusting the height of laparoscopic operating tables. JSLS 5: 7-12

12. Nguyen NT, Ho HS, Smith WD, Philipps C, Lewis C, De Vera RM, Berguer R (2001) An ergonomic evaluation of surgeons' axial skeletal and upper extremity movements during laparoscopic and open surgery. Am J Surg 182: $720-724$

13. Omar AM, Wade NJ, Brown SI, Cuschieri A (2004) Assessing the benefits of "gaze-down" display location in complex tasks. Surg Endosc 19: 105-108

14. Schoofs J, Gossot D (2004) A neglected but frustrating ergonomic issue: the thoracoscopic trocar. Min Invas Ther Allied Technol 13: 133-137

15. Uhrich ML, Underwood RA, Standeven JW, Soper NJ, Engsberg JR (2002) Assessment of fatigue, monitor placement, and surgical experience during simulated laparoscopic surgery. Surg Endosc 16: 635-639

16. Van Veelen MA (2003) Human-product interaction in minimally invasive surgery: a design vision for innovative products. TU Delft, Delft, The Netherlands

17. Van Veelen MA, Jakimowicz JJ, Goossens RHM, Meijer DM, Bussman JBJ (2002) Evaluation of the usability of two types of image display systems during laparoscopy. Surg Endosc 16: 674-678

18. Van Veelen MA, Kazemier G, Koopman J, Goossens RHM, Meijer DW (2002) Assessment of the ergonomically optimal surface height for laparoscopic surgery. J Laparoendosc Adv Surg Tech A 12: 47-52

19. Van Veelen MA, Nederlof EAL, Goossens RHM, Schot CJ, Jakimowicz JJ (2003) Ergonomic problems encountered by the medical team related to products used for minimally invasive surgery. Surg Endosc 17: 10771081

20. Van Veelen MA, Snijders CJ, Van Leeuwen E, Goossens RHM, Kazemier G (2003) Improvement of foot pedals used during surgery based on new ergonomic guidelines. Surg Endosc 17: 1086- 1091 